\title{
Enhancing Student Interest to Promote Learning in Science: The Case of the Concept of Energy
}

\author{
Georgia Toli *(D) and Maria Kallery (1) \\ Department of Solid-State Physics, School of Physics, Faculty of Natural Sciences, Aristotle University \\ of Thessaloniki, 54124 Thessaloniki, Greece; kallery@astro.auth.gr \\ * Correspondence: tolig@auth.gr
}

Citation: Toli, G.; Kallery, M. Enhancing Student Interest to Promote Learning in Science: The Case of the Concept of Energy. Educ. Sci. 2021, 11, 220. https://doi.org/ 10.3390/educsci11050220

Academic Editor: Eila Jeronen

Received: 3 April 2021

Accepted: 29 April 2021

Published: 6 May 2021

Publisher's Note: MDPI stays neutral with regard to jurisdictional claims in published maps and institutional affiliations.

Copyright: (c) 2021 by the authors. Licensee MDPI, Basel, Switzerland. This article is an open access article distributed under the terms and conditions of the Creative Commons Attribution (CC BY) license (https:/ / creativecommons.org/licenses/by/ $4.0 /)$.

\begin{abstract}
This paper presents an intervention aiming to promote students' learning by enhancing their interest in the concept of energy. Junior high school students' learning and interest is evaluated after engaging in activities on work and energy. The intervention integrated hands-on and simulated experiments included a structured series of guided investigative tasks and whole-class discussions. The intervention was delivered to an experimental group consisting of 110 junior high school students. The control group consisted of 96 students of the same grade level, where students were taught about energy in the traditional sense, i.e., via the standard textbook. Written tests were then handed to all students to assess their learning outcomes. The results showed that the learning outcomes of students in the experimental group were significantly better than those of students in the control group. A notable increase in interest from students in the experimental group compared to that of the control group was also observed. Findings also showed a significant positive correlation between interest and academic achievement. This study reconfirms that enhancing interest could lead to better learning outcomes and its evidence-based methodology can be equally applied when introducing students to other difficult concepts of science.
\end{abstract}

Keywords: teaching energy; enhancing interest; energy in high school; high school physics; interest development; interest in science; science education

\section{Introduction}

The unifying role of energy in all fields of science explains many phenomena and confirms its multidimensional importance in education. Energy is recognized as a major learning objective in science, as it is considered a cornerstone for students' understanding of other concepts and phenomena in the physics curriculum. However, the concept of energy is not easily comprehended by students and its teaching methods have been the subject of much research in the field of education (e.g., [1]).

Researchers, over the course of several years, have attempted to teach young students the different components of energy, using different methods. For example, in Schmid's [2] approach, energy is not described as being 'derived' from fundamental quantities, such as force or mass, but instead is introduced as the primary quantity at the beginning of the physics course. Solomon [3] argues that the dissipation and degradation of energy should be taught in a simple way before its conservation as this eliminates difficulties. Newton [4] teaches gravitational potential energy, which, according to him, is not a concept that is easily comprehended by secondary school students, by employing a mechanism (Gravicar, a self-propelled vehicle), which was developed to make the concepts of "energy-mechanical, gravitational and potential meaningful" ([4], p. 310). Constantinou and Papadouris [5], drawing on the epistemology of science, proposed a teaching approach, the main features of which include the use "of theories to create models of phenomena, the distinction between states and processes, and the unifying nature of energy as an interpretive framework" ([5], p. 161). Millar [6] proposes a teaching sequence in which he suggests that energy 
resources are a good starting point to teach energy-related concepts, and Hertting [7] uses the physical model of Feynman's blocks to help students learn and internalize many of the abstract concepts related to energy.

However, studies have shown that many problems and difficulties still arise in young students' understanding of the concept of energy (e.g., [6,8]). These difficulties reduce their interest in the subject and energy becomes an unattractive area of study. We must therefore consider whether there are teaching strategies available that might ease some of the learner's difficulties.

Studies carried out over several past decades (e.g., [9-11]) have indicated that one of the most useful solutions is to trigger students' interest and optimize their active involvement and, therefore, their engagement in the learning process [9,11,12]. Engagement is directly linked to academic achievement [13] and is the result of a person's interest in content-specific activities [14]. Interest development takes place in two phases: The triggering phase and the maintaining phase [15-18].

Based on the above ideas, in the present study, we decided to approach the teaching of energy by first enhancing student interest in the topic. From the literature review, we were not able to identify works that used the same approach as in the present study, i.e., the focus on the phases of interest development, which we consider to be the innovative element of the teaching intervention implemented in the present study.

In view of all the above, in this paper, we present our intervention and explore whether, by enhancing students' interest in the subject of energy, we can achieve desired learning outcomes. Thus, our research question can be formulated as follows: Is there a positive correlation between students' learning outcomes and interest developed during our teaching intervention?

The present study was carried out in Greece and includes 2nd year junior high school students (aged 14). Greek junior high school is a total of 3 years.

The paper is organized according to the following sections: In the 'Background' section, the literature relevant to interest development and learning is reviewed. The 'Context' section includes a brief presentation of the concept of energy as it appears in the Greek high school curriculum and in our intervention. The 'Methodology' section includes subsections 'Design of the intervention', 'Implementation and data collection', and 'Data analysis and results', and finally, the 'Discussion' and 'Conclusions' are presented last.

\section{Background}

Researchers (e.g., [15,19]) have highlighted the role of interest as it boosts motivation and guarantees an individual's engagement in content-specific activities. It is a powerful driving factor that triggers and promotes learning and is considered essential for academic success [20]. Interest is characterized by increased attention, effort, and affect, experienced in any particular moment, as well as an enduring predisposition to reengage with a particular object or topic over time [15]. Interest appears to be especially important in attracting and sustaining students' attention (see $[17,21]$ ). Its presence ensures active and meaningful engagement in science classes, which is key to academic success and better learning outcomes [22-24].

Researchers classify interest in two types: situational and individual. While individual interest concerns personal interests one holds over time, situational interest is generated by a source external to the individual, such as an experiment or a demonstration that a teacher may conduct in the classroom. "Furthermore, interest is content specific and has a learning function. Situational interest has a relation to content such that it might be unexpected, novel, complex, or mysterious, which makes salient a gap in one's knowledge-a gap that motivates people to engage with the content" ([14], p. 50). Interest is strongly related to attention and can initiate exploration and learning [25].

Different sources that can generate interest and at the same time promote learning in science have been identified. Empirical studies provide evidence that conducting hands-on activities leads to positive motivational outcomes (e.g., [26,27]). Tural [28] observed that 
students were more motivated in the lesson with hands-on experiments than through traditional lessons and their interest piqued after teaching, work, and energy. Additionally, hands-on activities play a crucial role across all levels of inquiry-based learning in science education in order to develop students' knowledge and skills [29]. Djudin [30] advises the use of well-designed hands-on activities as they spark students' interest while achieving the expected learning outcomes.

Another influential factor that stimulates students' interest is the connection between what they learn and real-life contexts, as this addresses topics that are relevant and applicable to their lives. As Djudin ([30], p. 20) notes, "the students are more engaged when they feel that what they are learning is connected to life outside the classroom".

Researchers and educators have also highlighted the contribution of software. Software, in addition to pushing interest and motivation to learn, also contributes to conceptual understanding. The use of educational software as a tool in teaching and learning also increases learners' skills that are needed during their school life. "It also helps in providing a proactive environment between the student and the teacher from one side and among students from another side", increasing their advancement and leading them toward better learning outcomes ([31], p. 1602). It has also been found that computer simulations spark and increase students' interest, actively engaging them in investigations, while, at the same time, maintaining their motivation in learning science $[32,33]$. According to Smetana and Bell ([34], p. 1338), "computer simulations provide many advantages to support calls for inquiry-based, learner- and knowledge-centered instruction [35]". They promote students' interest and thus active engagement in problem-solving situations (see [36,37]) and assist students in acquiring a more concrete knowledge of abstract concepts [38]. In computer simulations, learners study situations similar to those they encounter in their daily lives within a framework of natural phenomena and solve practical exercises after studying the educational material [31]. They interact with representations of natural phenomena that would otherwise be impossible to observe, a process that helps them to formulate scientifically correct explanations for these phenomena [33].

As presented in the introduction, the development of situational interest takes place in two phases: The phase of triggering and the phase of maintaining [15-18].

According to the model of Hidi ans Renninger [15], for the initial phase of interest development, the triggering phase, it is necessary that the teaching materials attract students attention and excites them. The second phase, the maintaining phase, calls for external factors, such as the content's perceived value (usefulness and importance), as prerequisites to sustain learners' attention and active participation. Both interest development phases result in developing knowledge and indirectly attribute value to the learning of energy (Figure 1).

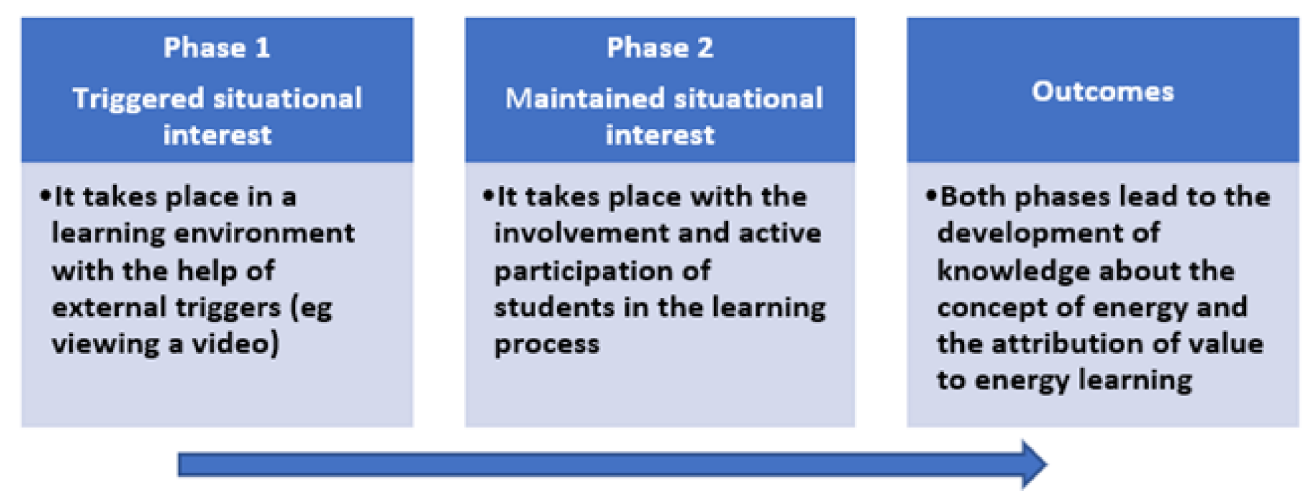

Figure 1. Situational interest development model and expected outcomes. 


\section{Context}

\subsection{Learning about Energy in a Greek Junior High School}

In the formal 2nd year Greek junior high school curriculum (where the concept of energy is first officially introduced), the chapter on energy includes the following topics: mechanical work of a constant force, kinetic energy, gravitational potential energy, and mechanical energy and its conservation. Each of these topics includes: the relevant theory, representations, numerical examples, and problems for students to solve. No experiments or other activities are proposed.

The main idea underlying the conceptual approach is that of dealing with a system, its surrounding environment, and the interactions between them [39]. The mathematical formalism of the concepts in the school textbook is as follows:

Work:

(a) $\mathrm{W}=\mathrm{F} \cdot \Delta \mathrm{r}$ (Force $\mathrm{F}$ along the direction of displacement $\Delta \mathrm{r}$ )

(b) $\mathrm{W}=-\mathrm{F} \cdot \Delta \mathrm{r}$ (Force $\mathrm{F}$ opposite the direction of displacement $\Delta \mathrm{r}$ )

(c) $\mathrm{W}=0$ (Force $\mathrm{F}$ is perpendicular to displacement $\Delta \mathrm{r}$ )

Kinetic energy $(K E)$ : $K=1 / 2 m \cdot v^{2}$ where $m$ is the mass and $v$ the speed of the body

Potential energy $(P E): \mathrm{U}=\mathrm{mgh}$ (gravitational potential energy of the system of an object of mass $\mathrm{m}$ ) and is valid only for objects near the surface of the Earth ( $h$ is the height and $g$ is approximately constant).

Mechanical energy and its conservation:

The total mechanical energy (EM) of a system is defined as the sum of KE and PE: $\mathrm{EM}=\mathrm{K}+\mathrm{U}$. In general, the EM of a system remains constant if gravitational, electric, and forces from springs act only.

The main learning objectives include:

Students shall:

- Understand the conditions that need to be met for work to be done.

- Define work as the product of force and displacement and identify its unit.

- Be able to realize when a force is doing positive, negative, or zero work.

- Understand that the kinetic energy of an object increases with speed and is proportional to the square of said speed.

- Understand that the gravitational potential energy of an object (near the surface of the Earth) is proportional to its mass and its vertical distance (height) from the surface.

- Understand that the gravitational potential energy of an object depends on the difference of vertical heights between the initial and final position of an object, instead of on the path along which the object moves.

- Understand that, in general, the mechanical energy of a body or a system remains constant if gravitational, electric, and forces from springs act only.

The way energy is usually taught in high school is via the standard textbook, classroom lectures, solving exercises on the board, and perhaps some demonstrations, often with little or no interaction with students. As mentioned earlier, no experiments or other activities are included in the textbook. The teacher usually assigns students exercises from the textbook to solve in class and/or at home.

\subsection{Energy in Our Intervention}

Our intervention includes the same topics as those in the curriculum, the same learning objectives, and shares the same premise, underlying the conceptual approach, i.e., that of dealing with a system, its surrounding environment, and the interactions between them. For our students' cognitive level, a system could be a single object or particle or a collection of objects or particles (e.g., [40]). The teaching approach of our intervention is presented in detail in the following section. 


\section{Methodology \\ Design of the Intervention}

Our intervention, based on Hidi and Renninger's [15] model of interest development, was designed to include two phases: first trigger situational interest and second maintain situational interest. The idea is that, when we develop each of these phases, we are more likely to meet our learning objectives.

Depending on the phase and learning objectives, different materials and activities were employed. Before selecting the materials and activities, whole class discussions were held to explore students' interests that could be linked to the concept of energy.

In the first phase, to trigger students' interest, videos for each of the energy topics were presented with popular cartoons or real-life situations (see Table 1). Each video screening was followed by a whole-class discussion.

Table 1. Activities in the phases of triggering and maintaining interest.

\begin{tabular}{|c|c|c|}
\hline TOPICS & $\begin{array}{c}\text { PHASE 1: Triggering Situational } \\
\text { Interest }\end{array}$ & PHASE 2: Maintaining Situational Interest \\
\hline Work (W) & $\begin{array}{l}\text { Videos of popular cartoons } \\
\text { and real-life situations, } \\
\text { available on Youtube } \\
\text { - Whole class discussions }\end{array}$ & $\begin{array}{l}\text { - Software (Simulations) } \\
\text { 1. Calculation of work according to different cases (force acting in the } \\
\text { direction of the displacement, force opposite the displacement) } \\
\text { 3. Dependence of } \mathrm{W} \text { on displacement (for a constant force) } \\
\text { - } \quad \text { Problem solving situations: Students' design and perform simple } \\
\text { experiments to solve problems }\end{array}$ \\
\hline Kinetic energy (KE) & $\begin{array}{l}\text { - } \quad \text { Videos (billiard, crash test) } \\
\text { - } \quad \text { Whole class discussions }\end{array}$ & $\begin{array}{l}\text { - } \\
\text { 1. } \\
\text { 2. Deperiments } \\
\text { car) } \\
\text { - } \quad \text { Software (Simulations) Dependence of KE on mass (qualitative study) } \\
\text { Dence of KE on speed (quantitative study using a Lego robot }\end{array}$ \\
\hline Potential energy (PE) & $\begin{array}{l}\text { Videos (pogo stick, } \\
\text { trampoline, pole-vault) } \\
\text { - Whole Class discussions }\end{array}$ & $\begin{array}{l}\text { - } \\
\text { 1. } \\
\text { Deperiments } \\
\text { 2. } \\
\text { constant) } \\
\text { Dependence of PE on height (qualitative study of a body with a } \\
\text { - } \\
\text { 1. } \\
\text { 2. Deftware (Simulations) } \\
\text { - } \quad \text { Dependence of PE on mass (quantitatively) }\end{array}$ \\
\hline $\begin{array}{l}\text { Mechanical energy (ME): } \\
\text { How energy converts from } \\
\text { one form to another }\end{array}$ & $\begin{array}{ll}\text { - } & \text { Videos (roller coaster) } \\
\text { - } & \text { Whole class discussions }\end{array}$ & $\begin{array}{l}\text { - } \\
\text { 1. } \\
\text { 2. } \\
\text { Pendulum (qualitative study) } \\
\text { apparatus (qualitative study) } \\
\text { - } \quad \text { Software (Simulations): converting PE to KE } \\
\text { PhET (converting PE to KE): } \\
\text { (https://phet.colorado.edu/el/simulation/energyskate-park-basics } \\
\text { (accessed on } 21 \text { March } 2021) \text { ) } \\
\text { Problem solving situations: Students design and perform simple } \\
\text { - } \quad \text { Conneriments to solve problems } \\
\text { Connections with real life situations: Visit to a hydroelectric dam. }\end{array}$ \\
\hline
\end{tabular}

In the maintaining phase, the activities were of different types. As noted earlier, our intervention is addressed to students at 2nd year junior high school (aged 14). Thus, 
we included simple age-appropriate activities that met the cognitive level of students to encourage and facilitate their conceptual understanding and were deemed effective for the purpose for which they had been selected: to meet the learning objectives of the intervention.

Drawing on the literature reviewed in the "background" section, to meet the objectives of the second phase (maintaining interest and achieving learning), we integrated investigative tasks with hands-on experiments to give students a so-called hands-on experience; a situational factor that is considered to evoke students' interest and their motivation to learn science (e.g., [26,27]. In addition to the experimental activities, in the maintaining phase, our intervention included the use of software designed by the authors and created by professional software developers. The software used in our intervention was the open code "GlowScript" platform with its programming language "VPython". This specific platform creates 3D models, which assist students to better comprehend physics experiments and phenomena. The software was interactive and included 3D simulated experiments with the objective to obtain an accurate output of the natural analogue and confirm that the experimental process was in fact understood by students, as well as ensure the teacher's ability to interact with the tool in order to guide the lesson. The software also included a structured series of guided investigative tasks, as well as specifically designed worksheets, all of which can successfully enhance instruction [41]. In the activities of the 2nd phase (the maintaining phase), in addition to the software created in-house, we included a PhET interactive simulation. PhET simulations, which can run online or can be downloaded for free, are often highly interactive, easy to use, and create environments that allow actions that would otherwise be difficult to show in the real world [41]. The PhET in our intervention was used as instructional material for an activity on mechanical energy, where students could work on converting potential energy to kinetic energy and vise-versa. Additionally, in both the triggering and maintaining phases, energy was associated with situations that students experience in everyday life.

Finally, within this context, the students were also given the opportunity to work autonomously, designing and executing simple experiments to solve problems and experience personal success, applying their skills in the process.

The classroom intervention included small-group work (4 students in each group), individual work, and teacher-mediated whole-class discussions.

The different types of activities for each topic included in both phases of interest development are presented in Table 1. The topics (work, kinetic energy, potential energy, and mechanical energy) were taught sequentially, taking into account both phases of interest development. Examples of representative activities are presented in Appendix A.

\section{Implementation and Data Collection}

Our intervention was delivered to 2nd year junior high school students. Two groups of students participated in the study: the experimental group, which was taught with our intervention and the control group, in which instruction strictly followed the school textbook. Both the experimental and control group participants attended regular public schools, located in the same city. Each group included students of the same class, i.e., whole classes were selected and assigned to either the experimental or control group. Students were registered in the public school system based on their home address. The control classes were in the school of the teacher who implemented the intervention.

The students of the experimental group $(\mathrm{N}=110)$ were taught the same concepts as those of the control group $(\mathrm{N}=96)$. For both groups, the subject was taught 2 hours a week.

To evaluate the learning outcomes of students in relation to the learning objectives, we administered a written questionnaire composed of 33 open-ended questions to both the experimental and control groups. The questionnaire was developed in collaboration with three fellow physics teachers, who taught the subject of energy to the same grade students in other schools. The questions varied in difficulty and examined whether students could apply the new knowledge they were taught to solve various energy-related problems, in line 
with the learning objectives. A sample of the test questions are presented in Appendix B. In the present study, it was decided that students' learning outcomes would be tested post-instruction only. No pre-test was administered because the post-test included items for which the students did not have any previous knowledge or experience. As mentioned earlier, students in the present study were first introduced to energy-related concepts in the respective class.

Students' situational interest was assessed with a self-report questionnaire, consisting of 13 items: 7 statements on triggered interest and 6 statements on maintained interest. Our questionnaire was based on the questionnaires constructed by Linnenbrink-Garcia et al. [42] and Doussay [43], used to measure interest in different academic situations. The questionnaires were translated into Greek and were appropriately adapted to the framework of our study. The final questionnaire drawn up for our study used a four-point Likert-type scale with options: Definitely agree, Slightly agree, Slightly disagree, Definitely disagree. Its reliability was calculated, giving a high Cronbach's alpha (0.879). A sample of items are presented in Appendix C.

\section{Data Analysis and Results}

First, we encoded students' answers. A value of 1 was assigned to the minimum average academic performance and minimum average interest and a value 4 was assigned to their maximum averages, respectively. We conducted a normality test, which indicated that the data were normally distributed using the SPSS 23 statistical package. The latter was also used to analyze the remaining data. We then performed an independent $t$-test that compared the mean difference between the two groups (experimental and control) for both interest and learning outcomes ([44]). The results showed a statistically significant difference between the two groups $(t(204)=9.41, p<0.05$ for learning and $t(204)=11.48$, $p<0.05$ for interest). These results are presented in Table 2 (situational interest) and Table 3 (learning outcome) as they appear in SPSS viewer.

Table 2. Results of independent $t$-test for situational interest (criterion $\mathrm{t}$ ).

\begin{tabular}{cccccccc}
\hline $\mathbf{F}$ & Sig & T & Df & $\begin{array}{c}\text { Mean } \\
\text { Difference }\end{array}$ & $\begin{array}{c}\text { Std. Error } \\
\text { Difference }\end{array}$ & Lower & Upper \\
\hline 8.50 & 0.00 & 9.41 & 204 & 1.25 & 0.13 & 0.99 & 1.51 \\
\hline
\end{tabular}

Table 3. Results of Independent t-test for learning outcome (criterion $t$ ).

\begin{tabular}{cccccccc}
\hline F & Sig & T & Df & $\begin{array}{c}\text { Mean } \\
\text { Difference }\end{array}$ & $\begin{array}{c}\text { Std. Error } \\
\text { Difference }\end{array}$ & Lower & Upper \\
\hline 4.28 & 0.04 & 11.48 & 204 & 1.44 & 0.13 & 1.19 & 1.69 \\
\hline
\end{tabular}

In the experimental group, the statistical analysis conducted on student answers to the questionnaire assessing learning outcomes recorded an average score of 3.51, with a standard deviation of 0.85 (3.51 $\pm 0.85(\mathrm{SD}))$, whereas the control group's average score was 2.26 , with a standard deviation of $1.04(2.26 \pm 1.04(\mathrm{SD}))$. Descriptive statistics concerning learning outcomes are presented in Table 4.

Table 4. Descriptive statistics concerning learning outcomes for both groups.

\begin{tabular}{ccccc}
\hline Group & $\begin{array}{c}\text { Number of } \\
\text { Participants } \\
\text { N }\end{array}$ & Mean & $\begin{array}{c}\text { Standard } \\
\text { Deviation (SD) }\end{array}$ & Std. Error Mean \\
\hline Experimental & 110 & 3.51 & 0.85 & 0.08 \\
Control & 96 & 2.26 & 1.05 & 0.20 \\
\hline
\end{tabular}


The average score for situational interest was 3.42, with a standard deviation of 0.81 for the experimental group ( $3.42 \pm 0.81$ (SD)) and 1.98, with a standard deviation of 0.98 for the control group (1.98 $\pm 0.98(\mathrm{SD}))$. Descriptive statistics concerning situational interest are presented in Table 5 .

Table 5. Descriptive statistics concerning situational interest for both groups.

\begin{tabular}{ccccc}
\hline Group & $\begin{array}{c}\text { Number of } \\
\text { Participants } \\
\text { N }\end{array}$ & Mean & $\begin{array}{c}\text { Standard } \\
\text { Deviation (SD) }\end{array}$ & Std. Error Mean \\
\hline Experimental & 110 & 3.42 & 0.81 & 0.08 \\
Control & 96 & 1.98 & 0.99 & 0.10 \\
\hline
\end{tabular}

The average scores on situational interest and learning outcomes are presented in Figure 2.

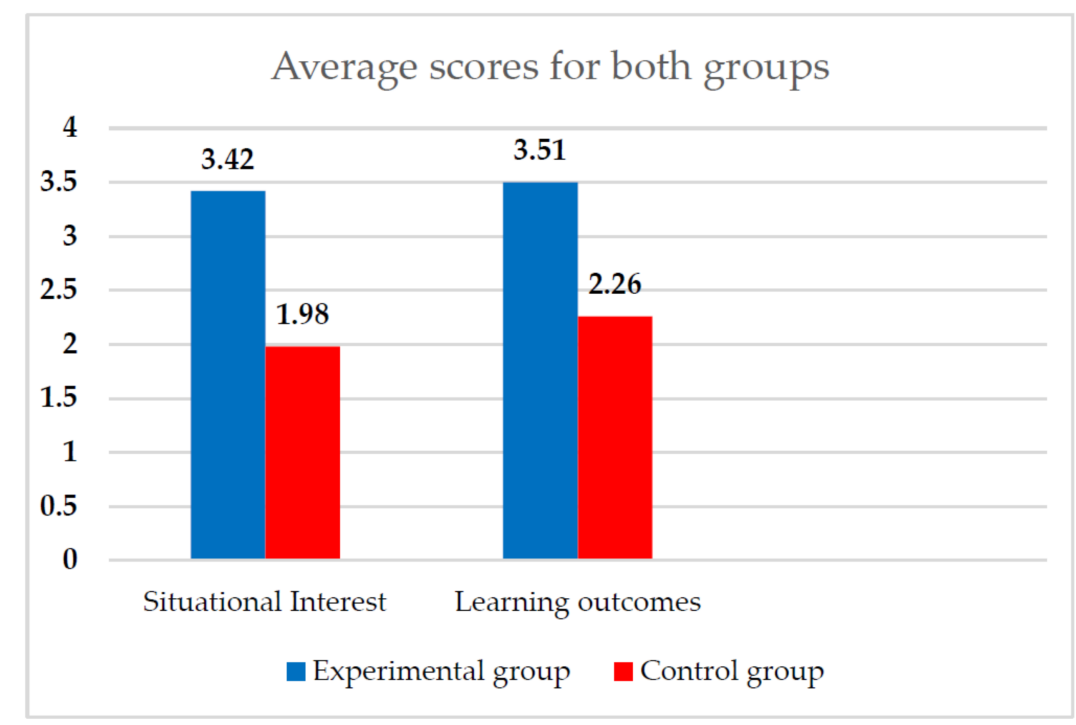

Figure 2. The average scores on situational interest and learning outcomes in the experimental and control groups.

Additionally, we examined the learning outcomes of both groups for each topic separately. The average score of learning outcomes concerning work, kinetic energy, potential energy, and mechanical energy for both groups was calculated and is presented in Table 6.

Table 6. Results of learning outcomes for all topics.

\begin{tabular}{ccccc}
\hline Topic & Work & Kinetic Energy & Potential Energy & Mechanical Energy \\
\hline Experimental & 3.44 & 3.49 & 3.55 & 3.52 \\
Control & 2.24 & 2.28 & 2.27 & 2.25 \\
\hline
\end{tabular}

We also performed an independent $\mathrm{t}$-test that compared the mean difference between the two groups (experimental and control) for all topics, and the results showed that there was a statistically significant difference between the two groups $(t(204)=8.82, p<0.05$ for work, $t(204)=9.03, p<0.05$ for kinetic energy, $t(204)=9.84, p<0.05$ for potential energy, and $t(204)=9.58, p<0.05$ for mechanical energy [44]. These results are presented in Table 7. 
Table 7. Results of independent $\mathrm{t}$-test (criterion $\mathrm{t}$ ) for all topics.

\begin{tabular}{ccccccccc}
\hline Form of Energy & F & Sig & T & Df & $\begin{array}{c}\text { Mean } \\
\text { Difference }\end{array}$ & $\begin{array}{c}\text { Std. Error } \\
\text { Difference }\end{array}$ & Lower & Upper \\
\hline Work & 4.99 & 0.03 & 8.82 & 204 & 1.20 & 0.14 & 0.93 & 1.46 \\
Kinetic energy & 10.75 & 0.00 & 9.03 & 204 & 1.21 & 0.13 & 0.95 \\
Potential energy & 13.491 & 0.00 & 9.84 & 204 & 1.28 & 0.13 & 1.03 & 1.54 \\
Mechanical energy & 7.04 & 0.01 & 9.58 & 204 & 1.27 & 0.13 & 1.00 \\
\hline
\end{tabular}

Finally, we examined the correlation between learning outcomes and situational interest by calculating the Pearson $r$ coefficient $(r(204)=0.846, p<0.001)()$. Its value indicates that there was a significant positive correlation between students' learning outcomes and their interest in the subject (highest values of $r$ lie between 0.80 and 0.99 ).

\section{Discussion}

The results of the present study show a significant difference in the interest of students in the experimental group compared to the control group. There is also a significant difference in the learning outcomes of the two groups. The average score of students in the experimental group, in addition to their scores in each of the individual concepts that our intervention evaluated, was significantly higher than that of the control group.

A particularly important finding of our study is the statistically significant positive correlation between interest and learning outcomes. This finding confirms that enhancing students' interest in the concept of energy can lead to successful learning outcomes [20], which answers our main research question. The students of the experimental group developed a high level of interest, which led to better academic performance in contrast to that of the control group. Specifically, the impact of students' interest on their learning is demonstrated by the results of the statistical analysis. Situational interest and learning outcome averages, as well as the values of criterion ' $t$ ', showed that there was a statistically significant difference between the averages of the experimental group students and those of the control group.

The results justify our reasoning to teach energy, following the phases of interest development in the subject matter [15]. They also confirm the findings of previous studies (e.g., $[9,10])$ which, as noted in the introduction, indicated that one of the most useful methods to teach difficult and unattractive subjects is to trigger students' interest and optimize their active involvement and, therefore, their engagement in the learning process $[9,12]$.

The encouraging results of our study can be attributed to a combination of factors, each of which we consider to have influenced the other factors, thereby contributing to both students' interest development and their learning.

(a) The creation of an appropriate learning environment and the choice of specific activities carried out by the students had a catalytic role in triggering and maintaining their interest, as well as their conceptual understanding. Stimulating interest was the first important step. But interest has to be sustained. This was ensured by selecting activities that were, on the one hand, enjoyable for the students and, on the other, age- and level-appropriate, and as such, their execution was feasible.

Investigative tasks, together with hands-on experiments, which, as noted earlier, provide the so-called hands-on experience, are considered to have evoked students' interest (e.g., $[26,27])$. Our findings are also in line with the findings of other studies reported earlier [28], where it was observed that students were more motivated in the lesson with hands-on experiments than through traditional lessons and their interest piqued after teaching, work, and energy.

(b) The software was one of the main instruction materials and was specifically designed to be simple to use for students. It assisted them in becoming acquainted with difficult ideas introduced in the present intervention. The specific interactive software with 3D simulations allowed students to experiment and carry out guided investigative tasks and interact with representations of the phenomena under study. This seems to have 
played a dominant role in students' conceptual understanding of the different forms of energy. Additionally, the high interest scores in energy from students of the experimental group were in line with the findings of other studies [32,33], which report that computer simulations spark and increase students' interest, actively engaging them in investigations that sustain their motivation to learn science.

(c) The selected approach, which provided students opportunities to engage in problem-solving situations while designing and performing simple experiments on their own, as well as the fact that they were given the opportunity to build constructions, enabled them to engage productively in their own learning. Additionally, we consider that a collaborative learning approach, together with classroom discussions, significantly influenced students' interest development and active involvement, therefore contributing to their learning. This view is also supported by the findings of other researchers (e.g., [45,46]), which also demonstrated that collaboration and idea exchange during science lessons is an approach that stimulates and develops students' interest and, as such, enhances their performance. This is also in line with the feedback given by the students themselves. The students specifically acknowledged the positive effects of this approach, thus reinforcing collaborative learning, together with idea exchanges (e.g., statements such as 'I liked working with my classmates', 'I liked sharing my ideas with my classmates').

Additionally, worth noting is that energy is related to everyday life, which we consider to also have contributed to students' interest and learning (see Table 1).

(d) The intervention was adapted to the cognitive level and age of the students. We had to make sure that the students of the experimental group would be able to perform at least equally in answering in-depth questions and solving the mathematical problems that were presented in the school textbook.

\section{Summary and Conclusions}

The concept of energy has a multidimensional importance for education. However, the understanding and interpretation of its essence is problematic for a significant number of junior high school students, even though it provides the cognitive background necessary for understanding and interpreting important phenomena in science. The difficulties encountered demotivate students to take interest in the subject, rendering it unattractive.

The present study provides an insight into how junior high school students, who are starting their formal education in physics, can be introduced to the concepts of energy. The didactic approach used in the present study differs in relation to others that teach energy and lies in the fact that student learning takes place during the two phases of interest development.

The present study demonstrates the importance of developing student interest and confirms the views expressed in the literature (e.g., $[9,12])$. Since interest is vital to students' active participation, engagement in activities, and effective learning, it is essential for teachers to include students' interest in their teaching methods when explaining difficult concepts, such as energy, especially at these ages.

The present study has important implications for practice and research. The approach presented in this paper could also be adapted and applied to teaching the concept of energy within the field of electricity in the upper grades of high school. This will help students form a holistic view on the concept of energy, which is central in most fields of the natural sciences. The teaching methodology used in the present study can also be employed with other difficult concepts of science. Additionally, the tool used to measure interest, which was adapted for the concept of energy, can be modified and used for corresponding measurements in similar teaching interventions to introduce other topics in science education as well.

The present study raises issues for further research. The limits of the approach adopted in our study is that its design targets the achievement of pre-established learning objectives without taking into account possible alternative ideas that students may have had about energy-related concepts. In a follow-up study, the design could be extended to include the exploration and use of the students' alternative ideas. 
While findings should be interpreted within the limitations of a study that, on the one hand, was carried out in a single country and, with an average number of students on the other, may be used to guide research and interpretation of the effects of teaching energy using the model of interest development in other countries.

Author Contributions: Data curation, G.T.; Formal analysis, G.T.; Methodology, G.T.; Supervision, M.K.; Validation, G.T.; Writing - review \& editing, G.T. Both authors have read and agreed to the published version of the manuscript.

Funding: This research received no external funding.

Institutional Review Board Statement: Not applicable.

Informed Consent Statement: Not applicable.

Data Availability Statement: Not applicable.

Conflicts of Interest: The authors declare no conflict of interest.

\section{Appendix A}

A. Quantitative study to determine the dependence of KE on speed

In this study, students used the "Lego robot car" of Figure A1. The Lego Robot car was programmed to move at a constant speed of four different values (not known to the students). Students, working in small groups, weighed the car and recorded its mass on their worksheet. They were then given chronometers and tape measures and were asked to measure and record their data for the variables, distance and time, and calculate the speed of the Lego robot car. Students then had to calculate the kinetic energy and plot the graph of Figure A2 in excel. Plotting graphs was deemed essential for students at this grade level, as the mathematics required for creating and interpreting graphs, as well as understanding the meaning of a linear function, are taught in the following grade. The latter causes students difficulty in understanding the linear relationship between two quantities by simply looking at the mathematical formula. Added to this is the fact that, in general, math is taught as a subject independent of physics. Additionally, as students at this level do not have the mathematical background to understand the notion of a parabolic curve, we decided to have them plot kinetic energy vs. the square of the speed $\left(v^{2}\right)$ to confirm a linear function (see Figure A2).

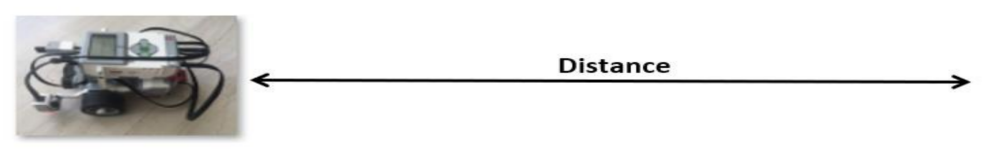

Figure A1. Lego robot car used in the quantitative study to determine the dependence of KE on speed. 


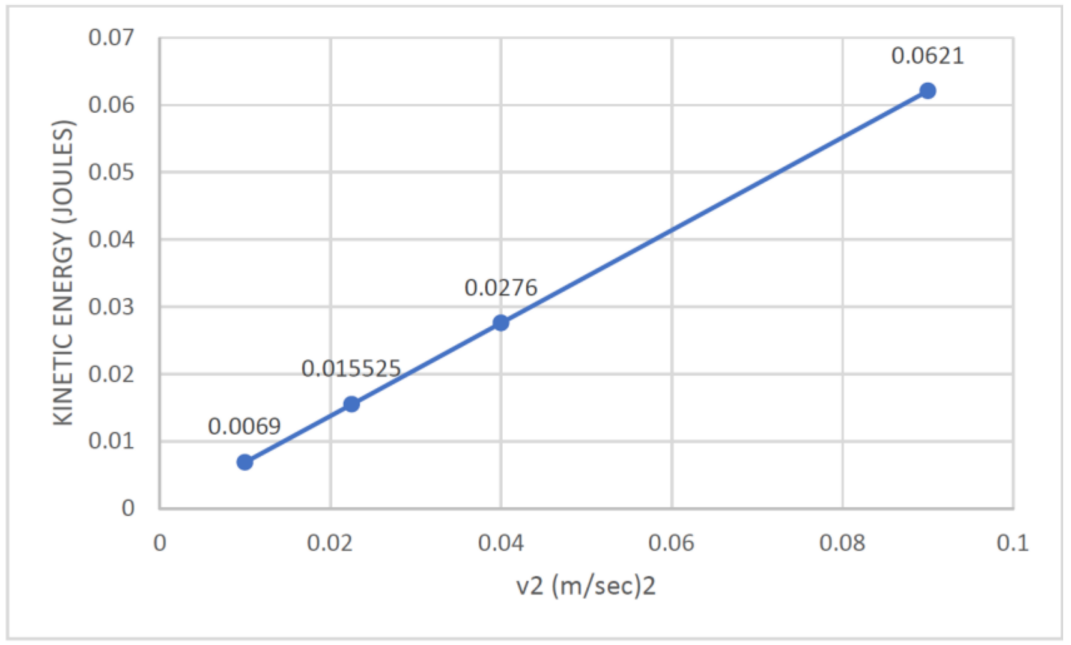

Figure A2. Graph plotted by the students: Dependence of kinetic energy on the square of speed.

\section{B. Qualitative study (experimentation): Transformation of PE to KE}

In this study, students experimented with the wheel and weight apparatus of the school laboratory called "the mechanical energy conservation device", shown in Figure A3, to observe the transformation of PE to KE. Having the car at a standstill, the students released the bob from a height and the trolley began to move. The students were then asked to interpret the observed phenomenon.

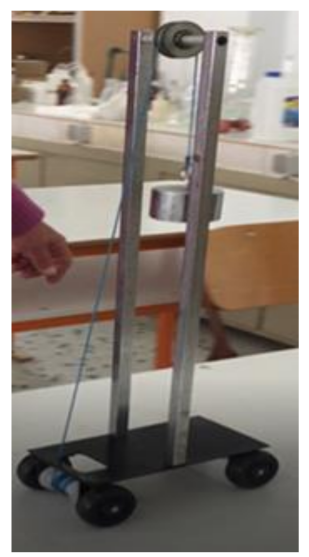

Figure A3. Wheel and weight apparatus used to observe the transformation of PE to KE.

C. Quantitative study (software): Transformation of PE to KE and conservation of ME.

Students used the software to evaluate the shift from PE to KE and the conservation of ME (see Figure A4). On the left screen shot, translated from Greek: Mechanical in blue, kinetic in red, and potential energy in green. Students could adjust the mass of the body and choose the height from which the body was released. The fall of the body was simulated with the software, the speed was measured independently at each position of the body, and the kinetic energy was calculated. As the body fell, students could see its KE increasing on the right screen shot as its PE decreased. At the same time, students could observe that its ME (blue line) remained constant. The phenomenon was then discussed in a whole-class discussion. 

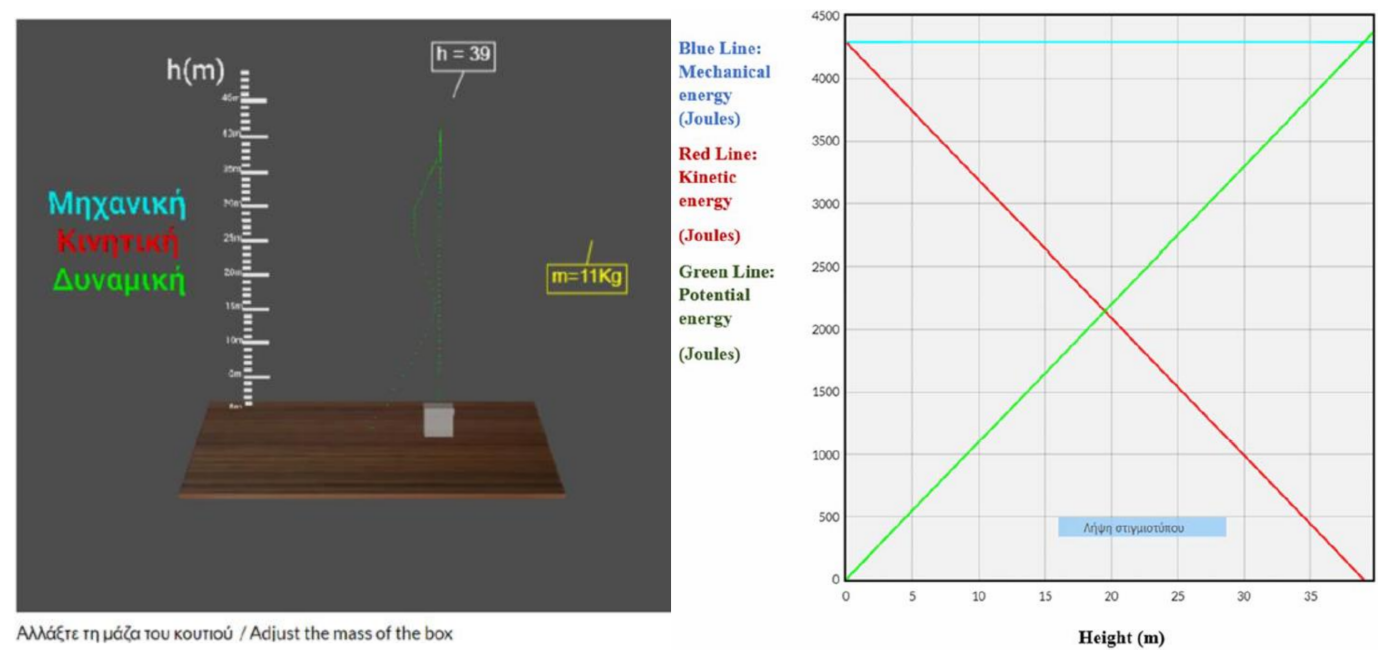

Figure A4. Transformation of PE to KE and the conservation of ME.

\section{Appendix B}

1. A weightlifter lifts a bar that weighs $1500 \mathrm{~N}$ at a height of $2 \mathrm{~m}$ from the ground. How much work does the athlete do as the force is exerted on the bar when he: (a) Lifts the bar at a constant speed; (b) Holds the bar still over his head; (c) Lowers the bar slowly to the ground at a constant speed?

Please justify your answer.

2. The mass $m$ of the figure rests on a table of height $h$. What is its potential energy (a) with respect to the ground and (b) with respect to the table?

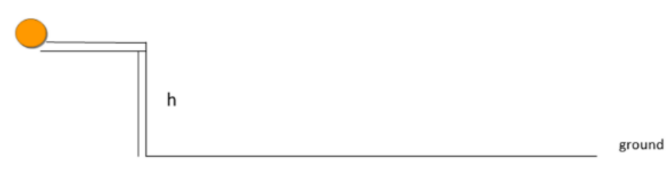

Figure A5. Mass resting on a table of height $h$

3. The bodies of the figure below have equal masses and one is thrown horizontally and the other vertically at the same speed and from the same height from the ground. (Frictions and resistances do not exist).

(a) Compare the mechanical energies of the bodies at the moment of launch.

(b) Calculate the velocity of each body if $\mathrm{H}=20 \mathrm{~m}$ (given $\mathrm{g}=10 \mathrm{~m} / \mathrm{s}^{2}$ )

Justify your answer.

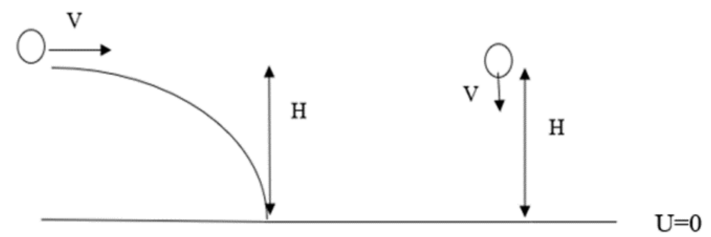

Figure A6. The two bodies thrown horizontally and vertically. 


\section{Appendix C}

Table A1. Sample of items of the situational interest questionnaire.

\begin{tabular}{|c|c|c|c|c|}
\hline & $\begin{array}{c}\text { Definitely } \\
\text { Agree }\end{array}$ & $\begin{array}{l}\text { Slightly } \\
\text { Agree }\end{array}$ & $\begin{array}{l}\text { Slightly } \\
\text { Disagree }\end{array}$ & $\begin{array}{c}\text { Definitely } \\
\text { Disagree }\end{array}$ \\
\hline \multicolumn{5}{|l|}{ My teacher teaches energy in a way that's exciting. } \\
\hline \multicolumn{5}{|l|}{$\begin{array}{l}\text { The lesson on energy is so much fun that it makes it easy for } \\
\text { me to follow. }\end{array}$} \\
\hline \multicolumn{5}{|l|}{ Studying energy is fascinating. } \\
\hline $\begin{array}{l}\text { I believe that what we are learning this year about energy is } \\
\text { especially useful to me. }\end{array}$ & & & & \\
\hline The things I learn about energy I can use in my everyday life. & & & & \\
\hline
\end{tabular}

\section{References}

1. Papadouris, N.; Constantinou, C.P. Investigating middle school students' ability to develop energy as a framework for analyzing simple physical phenomena. J. Res. Sci. Teach. 2016, 53, 119-145. [CrossRef]

2. Schmid, G.B. Energy and its carriers. Phys. Educ. 1982, 17, 212. [CrossRef]

3. Solomon, J. Teaching the conservation of energy. Phys. Educ. 1985, 20, 165-170. [CrossRef]

4. Newton, D.P. Teaching about energy with the Gravicar. Phys. Educ. 1989, 24, 310. [CrossRef]

5. Constantinou, C.P.; Papadouris, N. Teaching and learning about energy in middle school: An argument for an epistemic approach. Stud. Sci. Educ. 2012, 48, 161-186. [CrossRef]

6. Millar, R. Teaching about Energy: From Every day to Scientific Understandings. Sch. Sci. Rev. 2014, 96, 45-50.

7. Hertting, S. Energy Blocks-A Physical Model for Teaching Energy Concepts. Phys. Teach. 2016, 54, 31-33. [CrossRef]

8. Jewett, J.W., Jr. Energy and the confused student I: Work. Phys. Teach. 2008, 46, 38-43. [CrossRef]

9. Cohen, I.; Ben-Zvi, R. Improving student achievement in the topic of chemical energy by implementing new learning materials and strategies. Int. J. Sci. Educ. 1992, 14, 147-156. [CrossRef]

10. McGarity, J.R., Jr.; Butts, D.P. The relationship among teacher classroom management behavior, student engagement, and student achievement of middle and high school science students of varying aptitude. J. Res. Sci. Teach. 1984, 21, 55-61. [CrossRef]

11. Renninger, K.A.; Hidi, S. The Power of Interest for Motivation and Engagement; Routledge: London, UK, 2015.

12. Axelson, R.D.; Flick, A. Defining student engagement. Chang. Magaz. High. Learn. 2010, 43, 38-43. [CrossRef]

13. Bulger, M.E.; Mayer, R.E.; Almeroth, K.C.; Blau, S.D. Measuring learner engagement in computer-equipped college classrooms. J. Educ. Multim. Hyperm. 2008, 17, 129-143.

14. O'Keefe, A.P.; Horberg, E.J.; Plante, I. The Multifaceted Role of Interest in Motivation and Engagement. In The Science of Interest; Springer International Publishing: Berlin, Germany, 2017; pp. 49-67. [CrossRef]

15. Hidi, S.; Renninger, K.A. The four-phase model of interest development. Educ. Psychol. 2006, 41, 111-127. [CrossRef]

16. Krapp, A.; Prenzel, M. Research on interest in science: Theories, methods, and findings. Int. J. Sci. Educ. 2011, 33, 27-50. [CrossRef]

17. Mitchell, M. Situational interest: Its multifaceted structure in the secondary school mathematics classroom. J. Educ. Psychol. 1993, 85, 424. [CrossRef]

18. Schiefele, U. Situational and Individual Interest. In Handbook of Motivation at School; Routledge: London, UK, 2009; pp. 197-222.

19. Harackiewicz, J.M.; Smith, J.L.; Priniski, S.J. Interest matters: The importance of promoting interest in education. Policy Insights Behav. Brain Sci. 2016, 3, 220-227. [CrossRef] [PubMed]

20. Pressley, M.; El-Dinary, P.B.; Marks, M.B.; Brown, R.; Stein, S. Good strategy instruction is motivating and interesting. In The Role of Interest in Learning and Development; Lawrence Erlbaum: Mahwah, NJ, USA, 1992; pp. 333-358.

21. Hidi, S.; Baird, W. Interestingness-A neglected variable in discourse processing. Cogn. Sci. 1986, 10, 179-194. [CrossRef]

22. Rotgans, J.I.; Schmidt, H.G. Situational interest and academic achievement in the active-learning classroom. Learn. Instruct. 2011, 21, 58-67. [CrossRef]

23. Rotgans, J.I.; Schmidt, H.G. Situational interest and learning: Thirst for knowledge. Learn. Instruct. 2014, 32, 37-50. [CrossRef]

24. Wang, M.T.; Degol, J. Staying engaged: Knowledge and research needs in student engagement. Child Dev. Perspect. 2014, 8, 137-143. [CrossRef]

25. Silvia, P.J. Interest-The curious emotion. Curr. Direct. Psychol. Sci. 2008, 17, 57-60. [CrossRef]

26. Bergin, D.A. Influences on classroom interest. Educ. Psychol. 1999, 34, 87-98. [CrossRef]

27. Holstermann, N.; Grube, D.; Bögeholz, S. Hands-on activities and their influence on students' interest. Res. Sci. Educ. 2010, 40, 743-757. [CrossRef] 
28. Tural, G. Amazing physics: Learning about work, energy and projectile motion in a historical context. Phys. Educ. 2013, 48, 336. [CrossRef]

29. Trnova, E.; Trna, J. Hands-on experimental activities in inquiry-based science education. In Proceedings Book of the Joint International Conference MPTL; University of Ljubljana: Ljubljana, Slovenia, 2011; Volume 16, pp. 293-298.

30. Djudin, T. How to Cultivate Students' Interests in Physics: A Challenge for Senior High School Teachers. J. Pendidik. Sains 2018, 6 , 16-22. [CrossRef]

31. Younes, M.A.B. The Role of Educational Software in Improving the Performance of Students. Int. J. Sci. Eng. Res. 2015, 6, 1602-1606.

32. Lavonen, J. Learning and the Use of ICT in Science Education. Effective Use of ICT in Science Education; University of Edinburgh: Edinburgh, UK, 2008; pp. 6-28.

33. National Research Council. Learning Science through Computer Games and Simulations; National Academies Press: Washington, DC, USA, 2011.

34. Smetana, L.K.; Bell, R.L. Computer simulations to support science instruction and learning: A critical review of the literature. Int J. Sci. Educ. 2012, 34, 1337-1370. [CrossRef]

35. National Research Council. America's Lab Report: Investigations in High School Science; National Academies Press: Washington, DC, USA, 2006.

36. Hargrave, C.P.; Kenton, J.M. Preinstructional Simulations: Implications for Science Classroom Teaching. J. Comp. Math. Sci. Teach 2000, 19, 47-58. Available online: https:/ / www.learntechlib.org/primary/p/8063/ (accessed on 5 May 2019).

37. Lee, J. Effectiveness of computer-based instructional simulation: A meta analysis. Int. J. Instruct. Media 1999, $26,71$.

38. Ramasundaram, V.; Grunwald, S.; Mangeot, A.; Comerford, N.B.; Bliss, C.M. Development of an environmental virtual field laboratory. Comp. Educ. 2005, 45, 21-34. [CrossRef]

39. Knight, R.D. Physics for Scientists and Engineers; Pearson Higher Education: London, UK, 2017.

40. Serway, R.A.; Jewett, J.W. Physics for Scientists and Engineers; Cengage Learning: Boston, MA, USA, 2018.

41. Batuyong, C.T.; Antonio, V.V. Exploring the Effect of PhET®Interactive Simulation-Based Activities on Students' Performance and Learning Experiences in Electromagnetism. Asia Pac. J. Multidisc. Res. 2018, 6, 121-131.

42. Linnenbrink-Garcia, L.; Durik, A.M.; Conley, A.M.; Barron, K.E.; Tauer, J.M.; Karabenick, S.A.; Harackiewicz, J.M. Measuring situational interest in academic domains. Educ. Psychol. Meas. 2010, 70, 647-671. [CrossRef]

43. Dousay, T.A. Multimedia Design and Situational Interest: A Look at Juxtaposition and Measurement. In Educational Media and Technology Yearbook; Springer: Cham, Switzerland, 2014; pp. 69-82. [CrossRef]

44. Field, A. Discovering Statistics Using IBM SPSS Statistics; Sage: Newcastle upon Tyne, UK, 2013.

45. Adodo, S.O.; Gbore, L.O. Prediction of attitude and interest of science students of different ability on their academic performance in basic science. Int. J. Psychol. Counsel. 2012, 4, 68-72.

46. Fasli, M.; Michalakopoulos, M. Supporting active learning through game-like exercises. In Proceedings of the Fifth IEEE International Conference on Advanced Learning Technologies (ICALT'05), Kaohsiung, Taiwan, 5-8 July 2005; pp. 730-734. 